\section{Spectral Effects of Artificial Light on Plant Physiology and Secondary Metabolism: A Review}

\author{
Theoharis Ouzounis \\ Department of Food Science, Aarhus University, Kirstinebjergvej 10, \\ DK-5792, Aarslev, Denmark
}

Eva Rosenqvist

Department of Plant and Environmental Sciences, University of Copenhagen, Hoejbakkegaard Alle 9, DK-2630, Taastrup, Denmark

\section{Carl-Otto Ottosen ${ }^{1}$}

Department of Food Science, Aarhus University, Kirstinebjergvej 10, DK-5792, Aarslev, Denmark

Additional index words. light-emitting diodes, photosynthesis, chlorophyll fluorescence, phytochemicals, secondary metabolism, greenhouse horticulture

\begin{abstract}
With the expeditious development of optoelectronics, the light-emitting diode (LED) technology as supplementary light has shown great advancement in protected cultivation. One of the greatest challenges for the LED as alternative light source for greenhouses and closed environments is the diversity of the way experiments are conducted that often makes results difficult to compare. In this review, we aim to give an overview of the impacts of light spectra on plant physiology and on secondary metabolism in relation to greenhouse production. We indicate the possibility of a targeted use of LEDs to shape plants morphologically, increase the amount of protective metabolites to enhance food quality and taste, and potentially trigger defense mechanisms of plants. The outcome shows a direct transfer of knowledge obtained in controlled environments to greenhouses to be difficult, as the natural light will reduce the effects of specific spectra with species or cultivar-specific differences. To use the existing highefficiency LED units in greenhouses might be both energy saving and beneficial to plants as they contain higher blue light portion than traditional high-pressure sodium (HPS) lamps, but the design of light modules for closed environment might need to be developed in terms of dynamic light level and spectral composition during the day to secure plants with desired quality with respect to growth, postharvest performance, and specific metabolites.
\end{abstract}

Plants are capable of perceiving and processing information from their biotic and abiotic surroundings for optimal growth and development (Fankhauser and Chory, 1997). Light is one of the most important environmental cues that affect the developing plant and regulate its behavior (Whitelam and Halliday, 2007). Since plants are sessile, they need to be particularly plastic in response to their light environment. The diverse responses of plants to light entail sophisticated sensing of its quantity (fluence rate), quality (wavelength, i.e., color), direction, and duration (photoperiod) (Christie et al., 1999; Fankhauser and Chory, 1997). In many greenhouses in northern climates, supplemental lighting is needed from fall to spring to secure plant growth and development, as well as to obtain year-round high production and good quality plants. To date, the quality of most herbs and vegetable crops grown during the

Received for publication 17 Mar. 2015. Accepted for publication 1 June 2015.

${ }^{1}$ Corresponding author. E-mail: coo@food.au.dk.
(Marcelis et al., 2006). A recent review by Nelson and Bugbee (2014) claims lack of economic benefits of LED units comparing mainly U.S. produced lamps, where all tested HPS and LED units had a photon efficiency $\leq 1.7 \mu \mathrm{mol} \cdot \mathrm{W}^{-1}$. In northern Europe (UK and Denmark), independent measurements have shown efficiencies of commercially available Dutch and Danish LED fixtures of $2.2-2.4 \mu \mathrm{mol} \cdot \mathrm{W}^{-1}$, whereas the newest HPS (1000 W) show up to 2.1 $\mu \mathrm{mol} \cdot \mathrm{W}^{-1}$ (C. Dam-Hansen and S. Pearson, personal communication). Their light distribution is equal to or better than that of HPS lamps, so they are fully implementable in commercial scale. With the current energy prices, the payback time is now realisticespecially as some LED fixtures allow dynamic output with respect to intensity and spectra.

\section{LEDs and Use of Spectra}

Manipulation of the light spectrum of the lamps could trigger potential benefits by enhancing plant growth (Carvalho and Folta, 2014), but the HPS lamps do not provide the possibility for spectral manipulation or even dimming. As a consequence, the LED technology has emerged and developed rapidly in the past decades as alternative light sources (Massa et al., 2008). LEDs are solidstate and durable light sources providing a narrow spectrum of light (Stutte et al., 2009) in the range from ultraviolet to infrared. Their lifetime could reach up to $100,000 \mathrm{~h}$, in comparison with the HPS lamps with a lifetime ranging from 10,000 to 20,000 h (Bourget, 2008; Morrow, 2008; Sager and McFarlane, 1997). As LED use in greenhouses is developing, the prices are expected to gradually decrease and there has been a renewed interest in the use of LEDs as a tool in greenhouse research (Folta and Childers, 2008).

Because of its higher frequency and hence winter is far from the quality of summergrown crops.

In commercial practice, greenhouse plants are supplied with supplementary light for up to $16-20 \mathrm{~h}$ per day and the light intensity ranges between 100 and $200 \mu \mathrm{mol} \cdot \mathrm{m}^{-2} \cdot \mathrm{s}^{-1}$ (Paradiso et al., 2011), but lower levels are used for shade adapted species. Further north in Scandinavia, commercial installations of $300-500 \mu \mathrm{mol} \cdot \mathrm{m}^{-2} \cdot \mathrm{s}^{-1}$ are used for tomatoes (Lycopersicum esculentum) (M. Verheul, personal communication). The predominant greenhouse lighting sources are the HPS lamps because of their high efficiency (1.9 $\mu \mathrm{mol} \cdot \mathrm{m}^{-2} \cdot \mathrm{W}^{-1}$ ) in converting energy into photosynthetically active radiation $(P A R)$ (van Ieperen and Trouwborst, 2008). However, they are neither spectrally nor energetically optimal. They emit most radiation in the yellow and orange region with some red between 550 and $650 \mathrm{~nm}$, and only around $5 \%$ in the blue region between 400 and $500 \mathrm{~nm}$ (Sager and McFarlane, 1997). Because of the low levels of blue light fraction and other photosynthetic sensitive wavelengths, they are not the most efficient light sources in terms of light quality shorter wavelength, blue light contains more energy than red according to $E=h \nu=h c / \lambda$, where $E$ is the energy content of the photon $(\mathrm{J}), h$ is Planck's constant $\left(6.626 \times 10^{-34} \mathrm{Js}\right), \nu$ is the frequency $\left(\mathrm{s}^{-1}\right)$ of the light wave, $c$ is the speed of light, and $\lambda$ is the wavelength $(\mathrm{nm})$. Blue light is therefore more expensive to produce than red light. The use of blue and red LEDs has been the prime selection for producers as these wavelengths are efficiently absorbed by the primary plant pigments (chlorophylls), with red light being the most energy efficient in LED production. Both blue (420-450 nm) and red (600-700 $\mathrm{nm})$ lights are absorbed by chlorophyll $a$ (Chl a) which has its absorption peaks at 430 and $665 \mathrm{~nm}$ and chlorophyll $b(\mathrm{Chl} b)$ at $453 \mathrm{~nm}$ and $642 \mathrm{~nm}$ (Sager and McFarlane, 1997) (as shown in Fig. 1A). Although chlorophylls are the primary photosynthetic pigments, other accessory plant pigments such as carotenoids (Fig. 1A) and anthocyanins are capable of harvesting light. These accessory pigments work in conjunction with chlorophylls, which transfer light to the photosystems, dissipate 


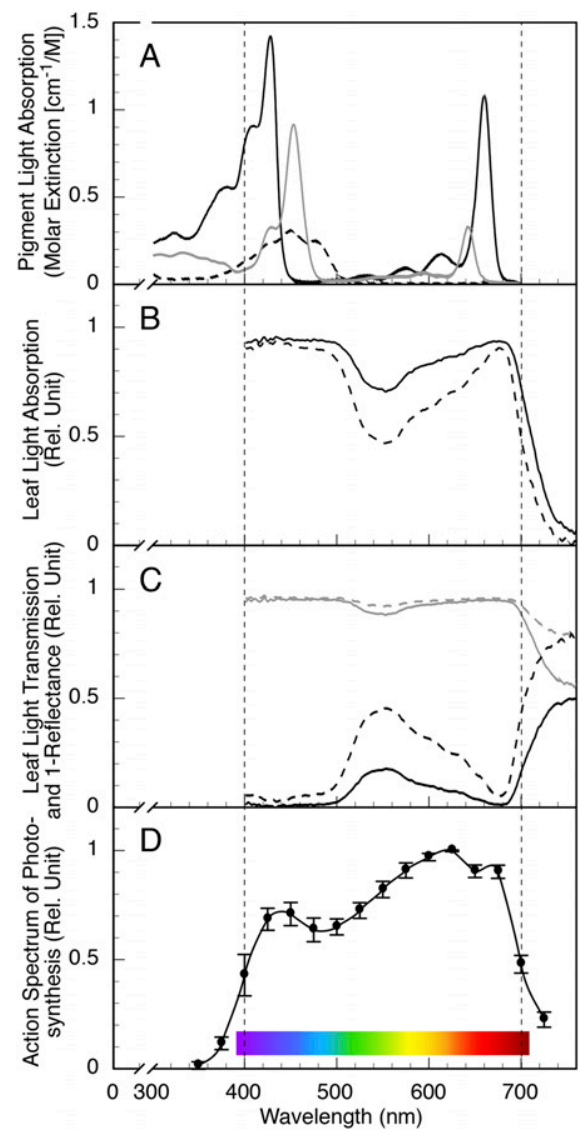

Fig. 1. Spectrum for pigments and leaves. (A) Absorption spectrum of chlorophyll $a$ (black line) and chlorophyll $b$ (gray line) in diethyl ether, and $\beta$-carotene (dashed line) in hexane based on data from http://omlc.ogi.edu/spectra/ PhotochemCAD/index.html. Other carotenoids like lutein and zeaxanthin have a similar absorption limit as $\beta$-carotene ( $c f$. Koning, 1994) in the green range above $492 \mathrm{~nm}$. (B) Light absorption in Chrysanthemum morifolium; fresh leaf (black line) and vacuum infiltrated by water (dashed line) to eliminate light scattering measured by a light integrating sphere (ASD Inc., Boulder, CO) and Avaspec2048 spectrometer (Avantes, Apeldoorn, The Netherlands). (C) 1-Reflectance (gray lines) and transmission (black lines) of the same fresh (solid lines) and vacuum infiltrated (dashed lines) leaves. (D) The relative quantum yield of photosynthesis of eight crop species (mean values $\pm \mathrm{SD}$ ) based on data from McCree (1972).

excess light energy, or work as antioxidants. As the chlorophyll and nonchlorophyll pigments have different absorption spectra, the result is a composite absorption spectrum that is broadened such that a wider range of radiation is absorbed by plants (Davies, 2004) (Fig. 1B).

The use of LED luminaries has the potential of passing significant energy savings to greenhouse growers. If this leads to economical savings, taking the investments in new lamps into consideration will depend on the energy prices in individual countries. The LED technology has yet to be fully integrated within the greenhouse control system and

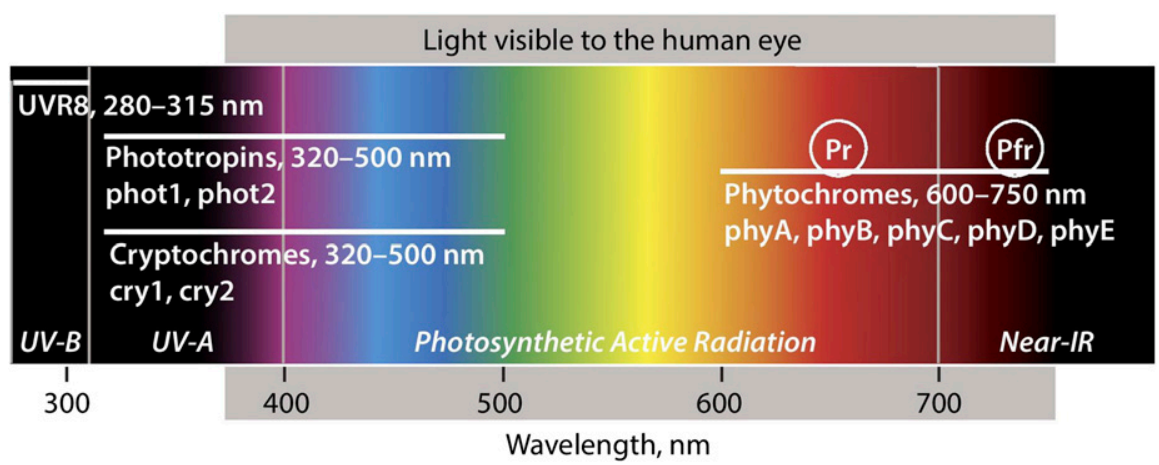

Fig. 2. The range of wavelengths that are sensed by the main plant photoreceptors (phytochromes, cryptochromes, phototropins, and UVR8) allowing light-driven developmental adaptations (data from http://www.biologie.ens.fr/smdgs/spip.php?article57).

should be optimized in terms of light output and distribution, whereas LED luminaire cost should be reduced to reach a sustainable and economically viable production (Morrow, 2008). In addition, LEDs emit less heat compared with the HPS lamps and often not in a downward direction. Consequently, the temperature inside the greenhouse might be affected depending on the design of the heating system and how much the heat radiation from the HPS lamps contributes to the canopy temperature of the crop. Based on unpublished data (C-O. Ottosen, personal communication), this varies between greenhouse and heating systems. Adjustments of air temperature may be needed to keep leaf temperature at the same degree and moving away from the fluctuation in heat radiation when the HPS lamps are turned on and off might require a change in screen use and ventilation strategies. For crops with lower leaf temperature requirements, LED lighting might actually be an advantage due to less heat load from the lamps and better humidity management due to reduced leaf temperature fluctuation.

Light quality, quantity, and duration are three parameters that concurrently influence plant growth (Casal and Yanovsky, 2005; Chen et al., 2004; Folta and Childers, 2008). The photosynthetic photon flux $(P P F)$ density (PPFD) represents the amount of photons $\left(\mu \mathrm{mol} \cdot \mathrm{m}^{-2} \cdot \mathrm{s}^{-1}\right)$ that is used for photosynthesis within the 400-700 nm waveband of PAR, where the most important wavelengths for photosynthesis are in the blue and red region. The "gap" with very low light absorption in the range $500-600 \mathrm{~nm}$ in isolated photosynthetic pigments (as shown in Fig. 1A) has disappeared in the intact leaf (as shown in Fig. 1B). This is because of light scattering in the leaves caused by the water-air interfaces between the water saturated cell walls and the air of the intracellular spaces. The light scattering increases the probability of absorption drastically, which is demonstrated if a leaf is vacuum infiltrated by, e.g., water (as shown in Fig. 1C) (DeLucia et al., 1996). The consequence is that green light absorbed more by intact leaves than by chlorophyll and carotenoids in solution. The light absorption only show a dip in the green part of the spectrum in fresh leaves (transmitting $\approx 13 \%$ in the range 500-600 $\mathrm{nm}$ in Chrysanthemum morifolium), which would be more pronounced (transmitting $\approx 36 \%$ ) if light scattering did not take place (as shown in Fig. 1C). The absorption spectrum in chlorophyll also means that the colors penetrate differently into the leaf. Blue and red are efficiently absorbed close to the surface, whereas green light contributes more to photosynthesis in deeper leaf layers (Brodersen and Vogelmann, 2010; Sun et al., 1998), which will decrease the potentially negative effect of the internal light gradient within the leaf.

The light absorption in leaves represents absorption in all pigments, including nonphotosynthetic pigments. Since some of the absorbed energy will not be delivered to the reaction centers of the two photosystems, the relative quantum yield of photosynthesis (as shown in Fig. 1D) will deviate from the absorption spectrum of the leaf (as shown in Fig. 1B). Although the dip in light absorption is at its lowest around $550 \mathrm{~nm}$, the dip in photosynthesis is found around $500 \mathrm{~nm}$ with two broad peaks around 400 and $620 \mathrm{~nm}$, and a shoulder around $670 \mathrm{~nm}$ (McCree, 1972). The lower efficiency in the blue range is caused by internal conversion in the chlorophyll molecule, where the extra energy in the blue photon, compared with a red, is lost as heat (Harbinson and Rosenqvist, 2003), since photosynthesis is fuelled by the number of photons absorbed independent of their individual energy content.

\section{Photoreceptors and the Role of Light Quality}

Plants possess distinct photoreceptors sensing ultraviolet-B, ultraviolet-A, blue, red, and far red light (as shown in Fig. 2). It is through these photoreceptors that plants sense the intensity, quality, direction, and duration of light (Fankhauser and Chory, 1997; Whitelam and Halliday, 2007). The main families of photoreceptors identified so far are the phytochromes, cryptochromes, phototropins, and UVR8. Phytochromes (phyA, phyB, phyC, phyD, phyE) absorb principally at the red/far red region of the 
light spectrum and have two spectrally distinct and photoreversible conformers, the red light absorbing form $\mathrm{P}_{\mathrm{r}}$ and the far red light absorbing form $\mathrm{P}_{\mathrm{fr}}$, which is the form that is active in the signaling pathway to regulate gene expression (Chen et al., 2004; Lin and Shalitin, 2003; Quail et al., 1995). Cryptochromes (cry1, cry2) and phototropins (phot1, phot2) absorb in the blue/ ultraviolet-A region (Ahmad and Cashmore, 1993; Briggs and Huala, 1999; Christie and Briggs, 2001; Lin and Shalitin, 2003; Whitelam and Halliday, 2007). UVR8 has been found to be responsible for sensing and absorbing ultraviolet light in the range of 280-315 nm, initiating plant stress responses (Jenkins, 2009; Kaiserli and Jenkins, 2007). Phytochromes and cryptochromes have also been reported to act as green light photoreceptors (Folta and Maruhnich, 2007). Green light affects plant responses via cryptochromedependent and cryptochrome-independent means, the green absorbing state of cry 1 and cry2 reserves blue light-induced responses (Banerjee et al., 2007; Bouly et al., 2007; Folta and Maruhnich, 2007). All photoreceptors mediate the light-dependent development of plants, a process called photomorphogenesis. The signaling pathways of the aforementioned photoreceptors are integrated to fine-tune the photosynthetic status of the plant to everchanging environmental light (de Carbonnel et al., 2010).

Early studies on spectral effects were focused on photomorphogenesis in relation to phytochrome and the red/far red ratio often using narrow band filters and fluorescent tubes (Buck and Vince-Prue, 1985; Moe et al., 1991; Mortensen, 1990). More recent studies have broadened the knowledge of how phytochromes function, showing that they are essential for germination, deetiolation, stem elongation, and flowering as well as for fine-tuning vegetative development by influencing gravitropism, phototropism, and shade-avoidance responses (Casal, 2013; Chen et al., 2004; Fankhauser and Chory, 1997; Saebø et al., 1995). A large body of photobiological studies has shown that blue light acting through cryptochromes and phototropins is important for chlorophyll formation, stomatal opening, phototropism as well as photomorphogenesis (de Carbonnel et al., 2010; Dougher and Bugbee, 1998; Usami et al., 2004). In more detail, phot1 is proposed to mediate leaf positioning and phototropism under low light intensity, whereas phot 2 gets activated and acts redundantly with phot1 under higher light intensities (Demarsy and Fankhauser, 2009; Sakai et al., 2001). Thus, under different or unfavorable conditions, such as high light intensity, phototropins are suggested to improve the photosynthetic potential of plants.

Plants cannot optimally develop with monochromatic red light alone, and need blue and far red as well to regulate other types of responses besides photosynthesis and biomass production (Casal, 2006; Whitelam and Halliday, 2007). It has to be noted that a synergistic effect of phytochromes and cryptochromes ensues (Usami et al., 2004). The maximum effect in enhancing seedling morphology (longer hypocotyls as well as greater amount of anthocyanins) is achieved by a combination of blue and red light in Pinus sylvestris and Sorghum vulgare (Mohr, 1986, 1994). The amount of blue light required by different species (or even varieties) to create a specific response is an ongoing discussion (Ouzounis et al., 2014b); however, a certain unspecified amount of blue light is essential for maintaining a functional photosynthetic operation (Hogewoning et al., 2010). Further, when research is conducted in greenhouse conditions, the amount of natural light (that also encompasses blue light within) plays a role, as it could reverse physiological or chemical changes during an experiment (Ouzounis et al., 2014b). This could be in contrast with experiments conducted in growth chamber conditions where no natural light is present and, for example, significant changes in photosynthesis or flowering could be attributed solely to the presence of blue light (Terfa et al., 2012a, 2012b).

\section{Stomatal Regulation}

Stomatal opening is induced by both red and blue light and different mechanisms underlie this function (Briggs and Huala, 1999). At low PPFD (i.e., $15 \mu \mathrm{mol} \cdot \mathrm{m}^{-2} \cdot \mathrm{s}^{-1}$ ), blue light will cause stomatal opening with red light being ineffective. At higher PPFD, stomatal opening is consistently higher for blue than red light under the same PPFD level, thus making the process more sensitive to blue light (Ouzounis et al., 2014b; Savvides et al., 2012). Red-light-induced stomatal opening results from a guard cell response to a combination of intercellular reduction of $\mathrm{CO}_{2}$ concentration and a direct response of the guard cell chloroplasts to red light (Roelfsema and Hedrich, 2005; Shimazaki et al., 2007). Phot 1 and phot 2 function as the blue light receptors and are involved in the stomatal response, contributing to increased stomatal conductance $\left(g_{\mathrm{S}}\right)$ (Doi et al., 2004; Huala et al., 1997; Kinoshita et al., 2001). Stomatal conductance is used as a measure of stomatal opening, which is the rate of passage of $\mathrm{CO}_{2}$ entering or water vapor exiting through the stomata of a leaf (Assmann, 1988; Taiz and Zeiger, 2010). Stomatal conductance in leaves subjected to blue and red light is typically higher than the sum of $g_{\mathrm{S}}$ under blue or red light alone, depicting a synergistic action of stomatal opening (Assmann, 1988; Iino et al., 1985; Ogawa et al., 1978). It is worth noting that an increase in $g_{\mathrm{S}}$ due to increasing blue light could be attributed to an additive or synergistic effect of stomatal traits with a longer response time, such as stomatal density, stomatal length, stomatal width, pore length or aperture (Boccalandro et al., 2012; Savvides et al., 2012). As blue light increases the number of stomata in chrysanthemum plantlets (Kim et al., 2004), it could also contribute to increased $g_{\mathrm{S}}$. Apparently, stomatal opening is governed by multiple features that should be taken into account for an overall realistic estimation of the regulation of the stomatal apparatus by the spectral composition of light.

\section{Roles of Protective Pigments in Light Responses}

The light environment is one of the most influential factors for the plant metabolite production (Carvalho and Folta, 2014; Kopsell and Sams, 2013) and exposure to varying wavelengths trigger physiological changes (Ouzounis et al., 2014a). In addition to primary metabolites, such as carbohydrates and amino acids, plants contain a vast variety of chemical compounds, distinct from the intermediates and products of primary metabolism, which are called secondary metabolites (SMs). Little is known about the physiological relationship between photosynthesis and secondary metabolism for ornamental or even edible greenhouse plants grown under LEDs, irrespective of whether they are grown in closed rooms or under natural light in greenhouses ( $\mathrm{Li}$ and Kubota, 2009; Ouzounis et al., 2015). Many SMs are key components for defense against herbivores, microbes, and viruses, as well as major contributors to specific odors, tastes, and colors of plants (Bennett and Walls-Grove, 1994).

Phenolic acids and flavonoids (examples and their absorbance spectra are shown in Fig. 3) represent an example of metabolic plasticity enabling plants to adapt to biotic and abiotic environmental changes (Wink, 2010). Phenolic compounds are located in the cuticle, epidermis, and/or mesophyll (Solovchenko and Merzlyak, 2008). The concentration of these compounds depends on season and varies at different stages of growth and development (Lynn and Chang, 1990). Plant phenolics have key roles as blue and red pigments, but also as antioxidants and ultraviolet light screens (Lattanzio et al., 2006). Thus their established roles are clearly ecological in nature. Plants need phenolic compounds for a variety of reasons. Specifically for phenolic acids, chlorogenic acid

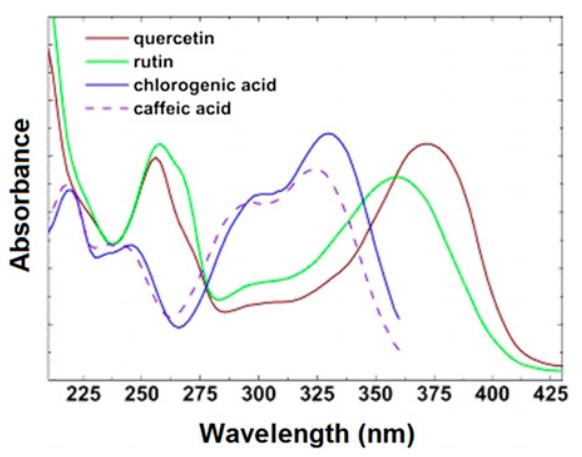

Fig. 3. Absorbance spectra of certain phenolic compounds, where quercetin and rutin represent flavonoids, and chlorogenic and caffeic acid represent phenolic acids (published with permission, http://www.photobiology.info/ Solovchenko.html). 


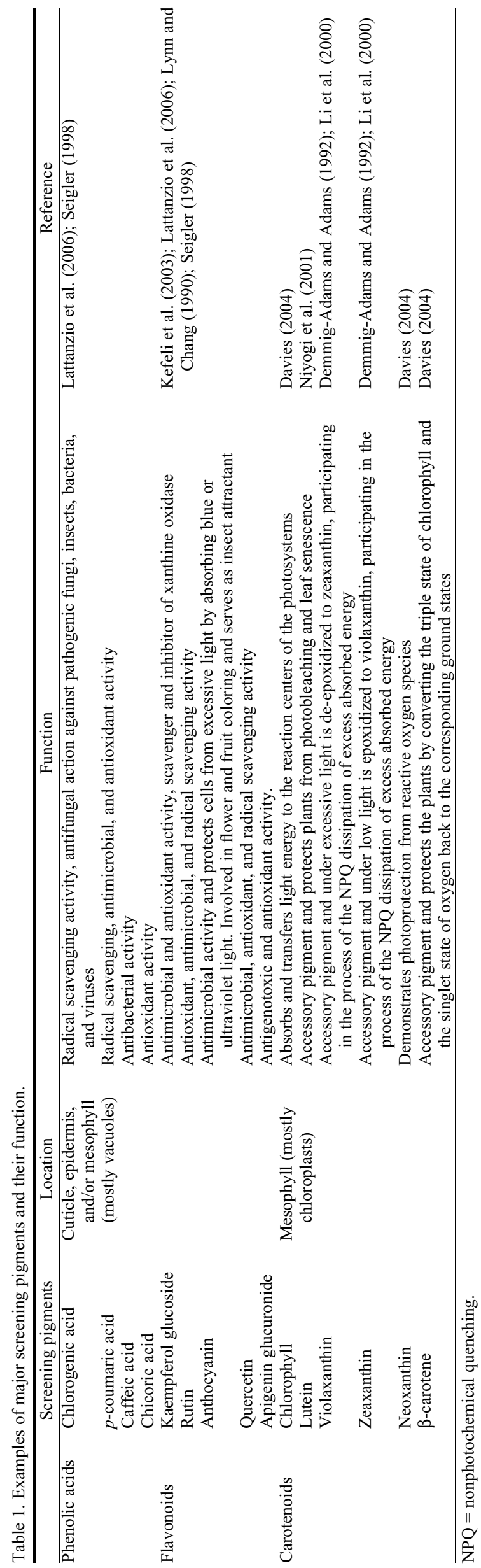

shows radical scavenging activity, antifungal action against pathogenic fungi, and acts against insects, bacteria, and viruses; $p$ coumaric acid also exhibits radical scavenging, antimicrobial, and antioxidant activity; caffeic and chicoric acid have antibacterial and antioxidant activity, respectively (Lattanzio et al., 2006; Seigler, 1998; Wink, 2010).

With respect to flavonoids, kaempferol glucoside displays both antimicrobial and antioxidant activity and is an efficient scavenger and inhibitor of xanthine oxidase [an enzyme that generates reactive oxygen species (ROS)] and has metal ion chelating properties (Seigler, 1998). Rutin and quercetin also demonstrate antioxidant, antimicrobial, and radical scavenging activity. Apigenin glucuronide is another flavonoid showing antioxidant and antigenotoxic activity, and which inhibits bacterial growth and has pathogenic and symbiotic interactions with microorganisms. Anthocyanins are involved in flower and fruit color and can serve as an insect attractant; however, at the same time, they exhibit antimicrobial activity and protect cells from high light damage by absorbing blue or ultraviolet light (Seigler, 1998).

Carotenoids are orange and yellow accessory pigments found within chloroplasts and chromoplasts in the mesophyll (Solovchenko and Merzlyak, 2008), which provide protection, when plants are overexposed to light via harmless dissipation of excess energy, free radical detoxification, and thus limiting damage to membranes (Table 1). In addition, they contribute to photosynthesis by harvesting and transferring light energy to chlorophylls in a $P A R$ region of the spectrum, where chlorophyll absorption is lower (Davies, 2004). In the absence of carotenoids, excessive light will have detrimental effects on proteins and membranes.

The two major classes of carotenoids are the xanthophylls (e.g., lutein and violaxanthin) and the carotenes (e.g., $\beta$-carotene). In the xanthophyll cycle, the role of violaxanthin is crucial as under excessive light it is deepoxidized to zeaxanthin via antheraxanthin and under low light, zeaxanthin is again epoxidized to violaxanthin ( $\mathrm{Li}$ et al., 2000). This process is part of the light-regulated dissipation of excess absorbed energy [measured as nonphotochemical quenching (NPQ) of chlorophyll fluorescence], which possibly limits the formation of chlorophyll triplets and prevents ROS from being produced (Demmig-Adams and Adams, 1992). Lutein and $\beta$-carotene are also key components of the light-harvesting complex of leaves. To highlight the importance of lutein in plant photoprotection, Niyogi et al. (2001) showed that under high light intensity, photobleaching and leaf senescence were seen in the absence of lutein. Lutein absorbs blue light and appears yellow at low concentrations and orange-red at high concentrations; whereas $\beta$-carotene is able to convert the triplet state of chlorophyll and the singlet state of oxygen back to the corresponding ground states (Davies, 2004). 


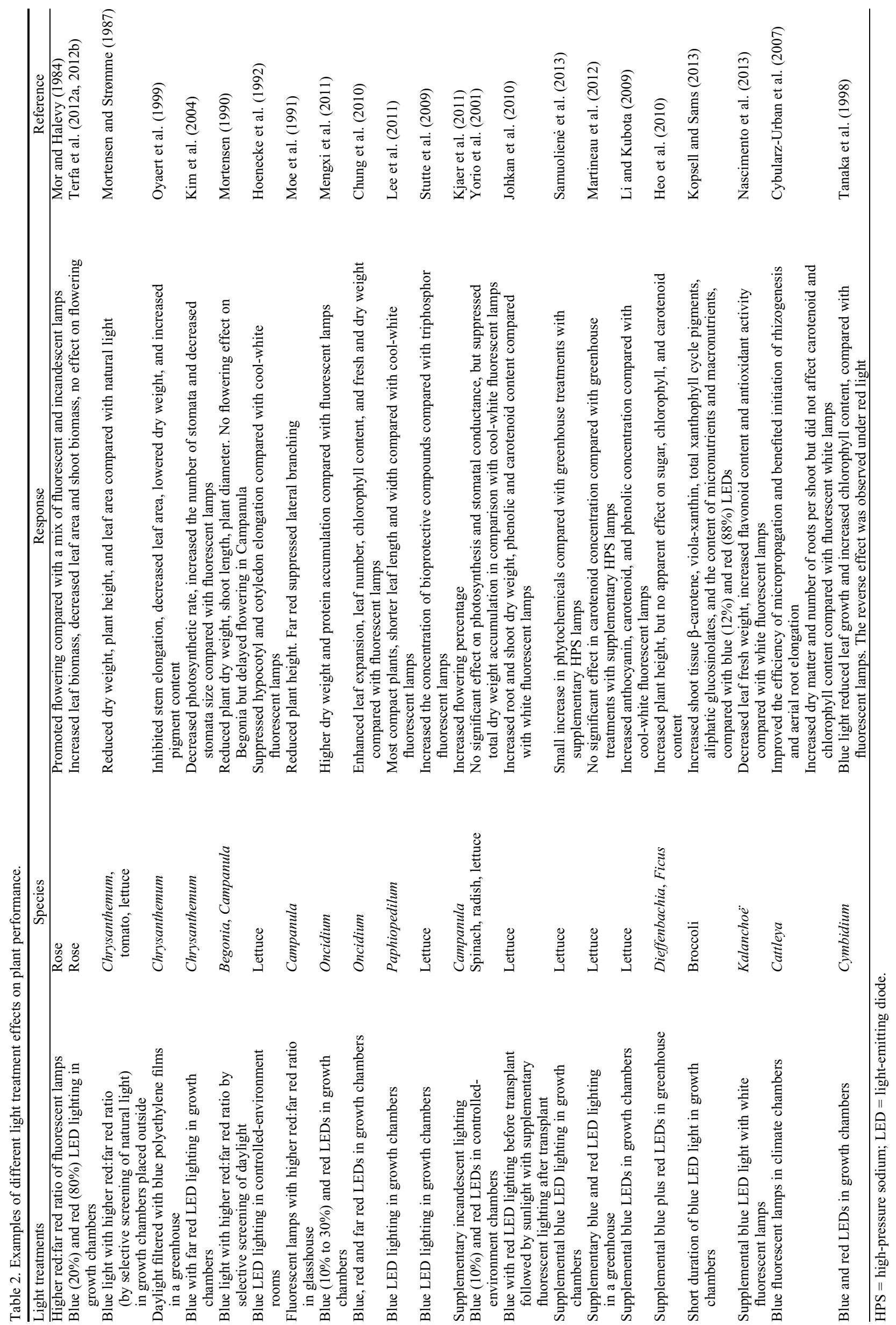




\section{Plant Reactions to Spectra}

Light interacts with the plant physiological processes in a variety of ways, and depending on the species and cultivars, irradiation can trigger stressful or nonstressful events for plants both in nature and production conditions. Previous studies on roses (Rosa hybrida cv. Marimba) have demonstrated that plant growth, photosynthesis, and flowering increased with increasing irradiance at low daily light integrals (DLIs), where light is limited and supplemental light is being used (Moe, 1997; Mor and Halevy, 1984). Recent studies showed that increased blue:red ratio from LEDs increased leaf biomass, decreased leaf area and shoot biomass, developed sun-adapted leaves, and had no effect on flowering in roses (Terfa et al., 2012a, 2012b). Earlier work on chrysanthemums (Chrysanthemum morifolium 'Ramat') has found that blue light with high red/far red ratio (by using growth chambers and color selective screens outdoors) reduced dry weight, plant height, and leaf area (Mortensen and Strømme, 1987). Later work has shown that blue light inhibited stem elongation, increased pigment content, decreased leaf area, and lowered total dry weight when daylight was filtered with blue polyethylene films in a greenhouse (Oyaert et al., 1999). In chrysanthemum plantlets, blue and red LED lighting increased the photosynthetic rate compared with blue or red light alone, whereas greater stem length was obtained with the combination of red with far red instead of blue with far red light; blue light increased the number of stomata and decreased stomata size, whereas the combination of blue and red light decreased the number of stomata and increased their size (Kim et al., 2004). Plant dry weight, shoot length, and plant diameter were reduced in both Begonia $\times$ hiemalis and Campanula isophylla after exposure to blue light compared with natural light (Mortensen, 1990). The combination of low natural light intensities and subsequent decrease in DLI reduced the flowering percentage of Campanulas but the effect was reversed after a continuous 19-h photoperiod by incandescent lamps (Kjaer et al., 2011). In addition, far red light seems to promote stem elongation and lateral branching in Campanula in comparison with fluorescent lamps (Moe et al., 1991). An overview of different spectral light treatments and their consequent effect on photomorphogenesis, photosynthesis, and secondary metabolism are presented in Table 2 .

The combination of blue and red LEDs resulted in higher dry weight in orchid (Oncidium 'Gower Ramsey') plantlets compared with fluorescent lamps (Mengxi et al., 2011). Red together with blue and far red light enhanced leaf expansion, leaf number, fresh and dry weight, and chlorophyll content in orchids compared with red or blue light alone (Chung et al., 2010). Orchid seedlings grown under blue light had shorter leaf length and width than cool-white fluorescent lamps
(Lee et al., 2011). In lettuce (Lactuca sativa 'Grand Rapids'), blue light suppressed hypocotyl and cotyledon elongation compared with cool-white fluorescent lamps (Hoenecke et al., 1992). Blue (10\%) and red LEDs had no significant effect on $\mathrm{P}_{\mathrm{n}}$ (net photosynthesis, i.e., gross photosynthesis minus the respiration) and $g_{S}$ in lettuce in growth chambers, but suppressed total dry weight accumulation in comparison with cool-white fluorescent lamps (Yorio et al., 2001). Stutte et al. (2009) demonstrated that blue LEDs increased the concentration of bioprotective compounds in red leaf lettuce (L. sativa 'Outredgeous') compared with triphosphor fluorescent lamps. Cope and Bugbee (2013) analyzed different species subjected to warm/ cold white LEDs (warm white exhibit a yellowish color temperature with less amount of blue compared with cold white with bluish color temperature and higher amount of blue) and indicated that the blue component in cold white reduced elongation in contrast to warm whites, and suggested that leaf age as such also had an influence of the sensitivity to blue. Li and Kubota (2009) reported an increase in anthocyanins, xanthophylls, and $\beta$-carotene in baby leaf lettuce ( $L$. sativa ' Red Cross') in LED compared with cool-white fluorescent lamps. Similar results that highlight the importance of blue LED lighting in the production of SMs have been shown, such as an increase in the phenolic compounds and carotenoids in lettuce (Samuolienè et al., 2013). On the contrary, Martineau et al. (2012) found no significant difference in carotenoid concentration in lettuce when compared blue and red LED lighting to greenhouse treatments with supplementary HPS lamps.

Plant responses to light are species and/or cultivar dependent and could be influenced by a great deal of factors. It is known that the production of SMs is regulated by an interaction of environmental, physiological, biochemical, and genetic factors that diversely affect the SM content in individual plants. Apart from SMs, attention should be paid also to other compounds, such as carbohydrates, chlorophylls, as well as carbon and nitrogenous compounds to have a full picture of the plant's status.

\section{Conclusion}

The increasing demand for natural products and the rising world population boost the need for controlled growing systems using artificial lighting. These systems include greenhouses, growth chambers, vertical farming. Supplementary light (e.g., fluorescent, metal halide, or HPS lamps) was introduced to replace and/or mimic outdoor conditions, where the full spectral sunlight provides energy for photosynthetic organisms as well as to increase the production capacity. With higher efficiency adjustable LED lamps, protected plant cultivation will depend on these to reduce energy consumption and optimize plant growth. Changes in light intensity and wavelength can manipulate plant metabolism, thus the efficiency of LED can be used in favor of producing good-quality food in controlledenvironment agriculture. The current limitation in conversion to LED is both in terms of economy but also in a knowledge gap in how to use the LED to create the best possible quality of the crops since both species and cultivars vary in their responses.

It is worth mentioning that these horticultural light applications could be applied both on Earth and in space in the near future, and providing insights into plant physiology and metabolism can contribute to the feeding of the growing human population. Since food production relies on photosynthesis and metabolism, providing ample quality food for more than eight billion people as predicted in the next 40 years (Darko et al., 2014) and in areas with adverse environmental conditions is especially challenging. LED lighting is a very promising alternative in a wide range of horticulture, from propagation and floriculture to city farming of vegetables and fruits. Nowadays, we have the opportunity to manipulate growth and secondary products with LEDs, but specific patterns and consistent conclusions are still hard to come by.

\section{Literature Cited}

Ahmad, M. and A.R. Cashmore. 1993. HY4 gene of Arabidopsis thaliana encodes a protein with the characteristics of a blue light photoreceptor. Nature 366:162-166.

Assmann, S.M. 1988. Enhancement of the stomatal response to blue light by red light, reduced intercellular concentrations of $\mathrm{CO}_{2}$, and low vapour pressure differences. Plant Physiol. 87:226-231.

Banerjee, R., E. Schleider, S. Meier, R. MunozViana, R. Pokorny, M. Ahmad, R. Bittl, and A. Batschauer. 2007. The signaling state of Arabidopsis cryptochrome 2 contains flavin semiquinone. J. Biol. Chem. 282:14916-14922.

Bennett, R.W. and R.M. Wallsgrove. 1994. Secondary metabolites in plant defence mechanism. New Phytol. 127:617-633.

Boccalandro, H.E., C.V. Giordano, E.L. Ploschuk, P.N. Piccoli, R. Bottini, and J.J. Casal. 2012. Phototropins but not cryptochromes mediate the blue light-specific promotion of stomatal conductance, while both enhance photosynthesis and transpiration under full sunlight. Plant Physiol. 158:1475-1484.

Bouly, J.P., E. Schleider, M. Dionisio-Sese, F. Vandenbussche, D. Van der Straeten, N. Bakrim, S. Meier, A. Batschauer, P. Galland, R. Bittl, and M. Ahmad. 2007. Cryptochrome blue light photoreceptors are activated through interconversion of flavin redox states. J. Biol. Chem. 282:9383-9391.

Bourget, M.C. 2008. An introduction to lightemitting diodes. HortScience 43:1944-1946.

Briggs, W.R. and E. Huala. 1999. Blue-light photoreceptors in higher plants. Annu. Rev. Cell Dev. Biol. 15:33-62.

Brodersen, C.R. and T.C. Vogelmann. 2010. Do changes in light direction affect absorption profiles in leaves? Funct. Plant Biol. 37:403412.

Buck, M.F. and D. Vince-Prue. 1985. Photomodulation of stem extension in light-grown plants: Evidence for two reactions. Plant Cell Physiol. 26(7):1251-1261. 
Carvalho, S.D. and K.M. Folta. 2014. Sequential light programs shape kale (Brassica napus) sprout appearance and alter metabolic and nutrient content. Hort. Res. 1:doi: 10.1038/ hortres.2014.8.

Casal, J.J. 2006. The photoreceptor interaction network, p. 407-437. In: E. Schafer and F. Nagy (eds.). Photomorphogenesis in plants and bacteria: Function and signal transduction mechanisms. Springer, Dordrecht, the Netherlands.

Casal, J.J. 2013. Photoreceptor signalling networks in plant responses to shade. Annu. Rev. Plant Biol. 64:403-427.

Casal, J.J. and M.J. Yanovsky. 2005. Regulation of gene expression by light. Int. J. Dev. Biol. 49:501-511.

Chen, M., J. Chory, and C. Fankhauser. 2004. Light signal transduction in higher plants. Annu. Rev. Genet. 38:87-117.

Christie, J.M., M. Salomon, K. Nozue, M. Wada, and W.R. Briggs. 1999. LOV (light, oxygen, or voltage) domains of the blue-light photoreceptor phototropin (nph1): Binding sites for the chromophore flavin mononucleotide. Proc. Natl. Acad. Sci. USA 96:8779-8783.

Christie, J.M. and W.R. Briggs. 2001. Blue light sensing in higher plants. J. Biol. Chem. 276:11457-11460.

Chung, J.P., C.Y. Huang, and T.E. Dai. 2010. Spectral effects on embryogenesis and plantlet growth of Oncidium 'Gower Ramsey'. Sci. Hort. 124:511-516.

Cope, K.R. and B. Bugbee. 2013. Spectral effects of three types of white light-emitting diodes on plant growth and development: Absolute versus relative amounts of blue light. HortScience 48:504-509.

Cybularz-Urban, T., E. Hanus-Fajerska, and A. Swiderski. 2007. Effect of light wavelength on in vitro organogenesis of a Cattleya hybrid. Acta Biol. Cracov. Ser. Bot. 49:113-118.

Darko, E., P. Heydarizadeh, B. Schoefs, and M.R. Sabzalian. 2014. Photosynthesis under artificial light: The shift in primary and secondary metabolism. Phil. Trans. R. Soc. B 369:20130243.

Davies, K. 2004. Plant pigments and their manipulation. Ann. Plant Reviews 14. Blackwell Publishing, Oxford, UK.

de Carbonnel, M., P. Davis, M.R. Roelfsema, S. Inoue, I. Schepens, P. Lariguet, M. Geisler, K. Shimazaki, R. Hangarter, and C. Fankhauser. 2010. The Arabidopsis phytochrome kinase substrate protein is a phototropin signaling element that regulates leaf flattening and leaf positioning. Plant Physiol. 152:1391-1405.

DeLucia, E.H., K. Nelson, T.C. Vogelmann, and W.K. Smith. 1996. Contribution of intercellular reflectance to photosynthesis in shade leaves. Plant Cell Environ. 19:159-170.

Demarsy, E. and C. Fankhauser. 2009. Higher plants use LOV to perceive blue light. Curr. Opin. Plant Biol. 12:69-74.

Demmig-Adams, B. and W.W.I.I.I. Adams. 1992. Photoprotection and other responses of plants to high light stress. Annu. Rev. Plant Physiol. Plant Mol. Biol. 43:599-626.

Doi, M., A. Shigenaga, T. Emi, T. Kinoshita, and K. Shimazaki. 2004. A transgene encoding a blue-light receptor, phot1, restores blue light responses in the Arabidopsis phot 1 phot2 double mutant. J. Expt. Bot. 55:517-523.

Dougher, T.A. and B.G. Bugbee. 1998. Is blue light good or bad for plants? Life Support Biosph. Sci. 5:129-136.

Fankhauser, C. and J. Chory. 1997. Light control of plant development. Annu. Rev. Cell Dev. Biol. 13:203-229.
Folta, K.M. and K.S. Childers. 2008. Light as a growth regulator: Controlling plant biology with narrow-bandwidth solid-state lighting systems. HortScience 43:1957-1964.

Folta, K.M. and S.M. Maruhnich. 2007. Green light: A signal to slow down or stop. J. Expt. Bot. 58:3099-3111.

Harbinson, J. and E. Rosenqvist. 2003. An introduction to chlorophyll fluorescence. In: J.R. DeEll and P.M.A. Toivonen (eds.). Practical applications of chlorophyll fluorescence in plant biology. Kluwer Academic Publishers, Boston, MA.

Heo, J.W., Y.B. Lee, D.E. Kim, Y.S. Chang, and C. Chun. 2010. Effects of supplementary LED lighting on growth and biochemical parameters in Dieffenbachia amoena 'Camella' and Ficus elastica 'Melany'. J. Korean Hort. Sci. Tech. 28:51-58.

Hoenecke, M.E., R.J. Bula, and T.W. Tibbitts 1992. Importance of blue photon levels for lettuce seedlings grown under red-light emitting diodes. HortScience 27:427-430.

Hogewoning, S.W., G. Trouwborst, H. Maljaars, H. Poorter, W. van Ieperen, and J. Harbinson. 2010. Blue light dose-responses of leaf photosynthesis, morphology, and chemical composition of Cucumis sativus grown under different combinations of red and blue light. J. Expt. Bot. 61:3107-3117.

Huala, E., P.W. Oeller, E. Liscum, I.S. Han, E. Larsen, and W.R. Briggs. 1997. Arabidopsis NPH1: A protein kinase with a putative redox-sensing domain. Science 278:2120-2123.

Iino, M., T. Ogawa, and E. Zeiger. 1985. Kinetic properties of the blue light response of stomata. Proc. Natl. Acad. Sci. USA 82:8019-8023.

Jenkins, G.I. 2009. Signal transduction in responses to UV-B radiation. Annu. Rev. Plant Biol. 60:407-431.

Johkan, M., K. Shoji, F. Goto, S. Hashida, and T. Yoshihara. 2010. Blue light-emitting diode light irradiation of seedlings improves seedling quality and growth after transplanting in red leaf lettuce. HortScience 45:1809-1814.

Kaiserli, E. and G.I. Jenkins. 2007. UV-B promotes rapid nuclear translocation of the Arabidopsis UV-B specific signalling component UVR8 and activates its function in the nucleus. Plant Cell 19:2662-2673.

Kefeli, V., M. Kalevitch, and B. Borsari. 2003. Phenolic cycle in plants and environment. J. Cell. Mol. Biol. 2:13-18.

Kim, S.J., E.J. Hahn, J.W. Heo, and K.Y. Paek. 2004. Effects of LEDs on net photosynthetic rate, growth and leaf stomata of chrysanthemum plantlets in vitro. Sci. Hort. 101:143-151.

Kinoshita, T., M. Doi, N. Suetsugu, T. Kagawa, M. Wada, and K.I. Shimizaki. 2001. phot1 and phot 2 mediate blue light regulation of stomatal opening. Nature 414:656-660.

Kjaer, K.H., C.O. Ottosen, and B.N. Jørgensen. 2011. Cost-efficient light control for production of two campanula species. Sci. Hort. 129:825-831.

Koning, R.E. 1994. Light. Plant Physiology Information Website <http://plantphys.info/plant physiology/light.shtml $>$.

Kopsell, D.A. and C.E. Sams. 2013. Increases in shoot tissue pigments, glucosinolates, and mineral elements in sprouting broccoli after exposure to short-duration blue light from light emitting diodes. J. Amer. Soc. Hort. Sci. 138:31-37.

Lattanzio, V., V.M.T. Lattanzio, and A. Cardinali. 2006. Role of phenolics in the resistance mechanisms of plants against fungal pathogens and insects, p. 23-67. In: F. Imperato (ed.).
Phytochemistry: Advances in research, research signpost. Trivandrum, India.

Lee, Y.I., W. Fang, and C.C. Chen. 2011. Effect of six different LED light qualities on the seedling growth of Paphiopedilum orchid in vitro. Acta Hort. 907:389-391.

Li, Q. and C. Kubota. 2009. Effects of supplemental light quality on growth and phytochemicals of baby leaf lettuce. Environ. Expt. Bot. 67:5964.

Li, X.P., O. Björkman, C. Shih, A.R. Grossman, M. Rosenquist, S. Jansson, and K.K. Niyogi. 2000. A pigment-binding protein essential for regulation of photosynthetic light harvesting. Nature 403:391-395.

Lin, C. and D. Shalitin. 2003. Chryptochrome structure and signal transduction. Annu. Rev. Plant Biol. 54:469-496.

Lynn, D.G. and M. Chang. 1990. Phenolic signals in cohabitation: Implications for plant and development. Annu. Rev. Plant Physiol. Plant Mol. Biol. 41:497-526.

Marcelis, L.F.M., A. Elings, M. Bakker, E. Brajeul, J.A. Dieleman, P.H.B. de Visser, and E. Heuvelink. 2006. Modelling dry matter production and partitioning in sweet pepper. Acta Hort. 718:121-128.

Martineau, V., M.G. Lefsrud, M. Tahera-Naznin, and D.A. Kopsell. 2012. Comparison of supplemental greenhouse lighting from light emitting diode and high pressure sodium light treatments for hydroponic growth of Boston lettuce. HortScience 47:477-482.

Massa, G.D., H.H. Kim, R.M. Wheeler, and C.A. Mitchell. 2008. Plant productivity in response to LED lighting. HortScience 43:1951-1956.

McCree, K.J. 1972. The action spectrum, absorptance and quantum yield of photosynthesis in crop plants. Agr. Meteorol. 9:191-216.

Mengxi, L., X. Zhigang, Y. Yang, and F. Yijie. 2011. Effects of different spectral lights on Oncidium PLBs induction, proliferation, and plant regeneration. Plant Cell Tiss. Org. 106:1-10.

Moe, R. 1997. Physiological aspects of supplementary lighting in horticulture. Acta Hort. 418:17-24.

Moe, R., R.D. Heins, and J. Erwin. 1991. Stem elongation and flowering of the long-day plant Campanula isophylla 'Moretti' in response to day and night temperature alternations and light quality. Sci. Hort. 48:141-151.

Mohr, H. 1986. Coaction between pigment systems, p. 547-564. In: R.E. Kendrick and G.H. M. Kronenberg (eds.). Photomorphogenesis in plants. Martinus-Nijhoff, Dordrecht, the Netherlands.

Mohr, H. 1994. Coaction between pigment systems, 2nd ed, p. 353-373. Photomorphogenesis in plants. In: R.E. Kendrick and G.H.M. Kronenberg (eds.). Kluwer Academic Publishers, Dordrecht, the Netherlands.

Mor, Y. and A.H. Halevy. 1984. Dual effect of light on flowering and sprouting of rose shoots. Physiol. Plant. 61:119-124.

Morrow, R.C. 2008. LED lighting in horticulture. HortScience 43:1947-1950.

Mortensen, L. and E. Strømme. 1987. Effects of light quality on some greenhouse crops. Sci. Hort. 33:27-36.

Mortensen, L.M. 1990. Effects of temperature and light quality on growth and flowering of Begonia xhiemalis Fotsch. and Campanula isophylla Moretti. Sci. Hort. 44:309-314.

Nelson, J.A. and B. Bugbee. 2014. Economic analysis of greenhouse lighting: Light emitting diodes vs. high intensity discharge fixtures. PLoS One 9(6):e99010.

Nascimento, L.B., M.V. Leal-Costa, M.A. Coutinho, S. Moreora Ndos, C.L. Lage, S. Barbi, S. Ndos, 
S.S. Costa, and E.S. Tavares. 2013. Increased antioxidant activity and changes in phenolic profile of Kalanchoe pinnata (Lamarck) Persoon (Crassulaceae) specimens grown under supplemental blue light. Photochem. Photobiol. 89(2): 391-399.

Niyogi, K.K., C. Shih, W.S. Chow, B.J. Pogson, D. DellaPenna, and O. Björkman. 2001. Photoprotection in a zeaxanthin- and luteindeficient double mutant of Arabidopsis. Photosynth. Res. 67:139-145.

Ogawa, T., H. Ishikawa, K. Shimada, and K. Shibata. 1978. Synergistic action of red and blue light and action spectra for malate formation in guard cells of Vicia faba L. Planta 142:61-65.

Ouzounis, T., B. Razi Parjikolaei, X. Fretté, E. Rosenqvist, and C.O. Ottosen. 2015. Predawn and high intensity application of supplemental blue light decreases the quantum yield of PSII and enhances the amount of phenolic acids, flavonoids, and pigments in Lactuca sativa. Front. Plant Sci. doi: 10.3389/ fpls.2015.00019.

Ouzounis, T., X. Fretté, C.O. Ottosen, and E. Rosenqvist. 2014a. Spectral effects of LEDs on chlorophyll fluorescence and pigmentation in Phalaenopsis 'Vivien' and 'Purple Star'. Physiol. Plant. 154:314-327.

Ouzounis, T., X. Fretté, E. Rosenqvist, and C.O. Ottosen. 2014b. Spectral effects of supplementary lighting on the secondary metabolites in roses, chrysanthemums, and campanulas. J. Plant Physiol. 171:1491-1499.

Oyaert, E., E. Volckaert, and P.C. Debergh. 1999. Growth of chrysanthemum under coloured plastic films with different light qualities and quantities. Sci. Hort. 79:195-205.

Paradiso, R., E. Meinen, J.F.H. Snel, P. de Visser, W. van Ieperen, S.W. Hogewoning, and L.F. M. Marcelis. 2011. Spectral dependence of photosynthesis and light absorbtance in single leaves and canopy in rose. Sci. Hort. 127:548554.
Quail, P.H., M.T. Boylan, B.M. Parks, T.W. Short, Y. Xu, and D. Wagner. 1995. Phytochromes: Photosensory perception and signal transduction. Science 268:675-680.

Roelfsema, M.R. and R. Hedrich. 2005. In the light of stomatal opening: New insights into 'the Watergate'. New Phytol. 167:665-691.

Saebø, A., T. Krekling, and M. Appelgren. 1995. Light quality affects photosynthesis and leaf anatomy of birch plantlets in-vitro. Plant Cell Tissue Organ Cult. 41:177-185.

Sager, J.C. and J.C. McFarlane. 1997. Plant growth chamber handbook, Radiation, p. 1-29. In: R.W. Langhans and T.W. Tibbits (eds.). Iowa Agriculture and Home Economics Experimental Station Special Report no. 99. North Central Region Research Publication No. 340. Iowa State University Press, Ames, IA.

Sakai, T., T. Kawaga, M. Kasahara, T.E. Swartz, J.M. Christie, W.R. Briggs, M. Wada, and K. Okada. 2001. Arabidopsis nph1 and npl1: Blue light receptors that mediate both phototropism and chloroplast relocation. Proc. Natl. Acad. Sci. USA 98:6969-6974.

Samuoliene, G., A. Brazaitytè, R. Sirtautas, A Viršilè, J. Sakalauskaite, and S. Sakalauskienè. 2013. LED illumination affects bioactive compounds in romaine baby leaf lettuce. J. Sci. Food Agr. 93:3286-3291.

Savvides, A., D. Fanourakis, and W. van Ieperen. 2012. Co-ordination of hydraulic and stomatal conductances across light qualities in cucumber leaves. J. Expt. Bot. 63:1135-1143.

Seigler, D. 1998. Plant secondary metabolism. Kluwer Academic Publishers, Dordrecht, The Netherlands.

Shimazaki, K., M. Doi, S.M. Assmann, and T. Kinoshita. 2007. Light regulation of stomatal movement. Annu. Rev. Plant Biol. 58:219-247.

Solovchenko, A.E. and M.N. Merzlyak. 2008 Screening of visible and UV radiation as a photoprotective mechanism in plants. Russ. J. Plant Physiol. 55:719-737.

Stutte, G.W., S. Edney, and T. Skerritt. 2009. Photoregulation of bioprotectant content of red leaf lettuce with light-emitting diodes. HortScience 44:79-82.

Sun, J., N.N. Nishio, and T.C. Vogelmann. 1998. Green light drives $\mathrm{CO}_{2}$ fixation deep within leaves. Plant Cell Physiol. 39(10):1020-1026.

Taiz, L. and E. Zeiger. 2010. Plant physiology. 5th ed. Sinauer Associates, Sunderland, MA

Tanaka, M., T. Takamura, H. Watanabe, M. Endo, T. Yanagi, and K. Okamoto. 1998. In vitro growth of Cymbidium plantlets culture under superbright red and blue light-emitting diodes (LEDs). J. Hort. Sci. Biotechnol. 73:39-44.

Terfa, M.T., M.S. Poudel, A.G. Roro, H.R. Gislerød, J.E. Olsen, and S. Torre. 2012a. Light emitting diodes with a high proportion of blue light affects external and internal quality parameters of pot roses differently than the traditional high pressure sodium lamp. Acta Hort. 956:635-642.

Terfa, M.T., K.A. Solhaug, H.R. Gislerød, J.E. Olsen, and S. Torre. 2012b. A high proportion of blue light increases the photosynthesis capacity and leaf formation rate of Rosa $\times$ hybrida but does not affect time to flower opening. Physiol. Plant. 148:146-159.

Usami, T., N. Mochizuki, M. Kondo, M. Nishimura, and A. Nagatani. 2004. Cryptochromes and phytochromes synergistically regulate Arabidopsis root greening under blue light. Plant Cell Physiol. 45:1798-1808.

van Ieperen, W. and G. Trouwborst. 2008. The application of LEDs as assimilation light source in greenhouse horticulture: A simulation study. Acta Hort. 801:1407-1414.

Whitelam, G. and K. Halliday. 2007. Light and plant development. Blackwell Publishing, Oxford, UK.

Wink, M. 2010. Functions and biotechnology of plant secondary metabolites. Ann. Plant. Rev., Vol. 3. Wiley-Blackwell, Oxford, UK.

Yorio, N.C., G.D. Goins, H.R. Kagie, R.M. Wheeler, and J.C. Sager. 2001. Improving spinach, radish, and lettuce grown under red light emitting diodes (LEDs) with blue light supplementation. HortScience 36:380-383. 